\title{
Stabilization of fluorine in soil using calcium hydroxide and its potential human health risk
}

\author{
Seulki Jeong, Doyoung Kim, Hye-On Yoon ${ }^{\dagger}$ \\ Seoul center, Korea Basic Science Institute, 6-7, Seoul 02855, Republic of Korea
}

\begin{abstract}
This study assessed the stabilization of fluorine $(\mathrm{F})$-contaminated soil using calcium hydroxide $\left(\mathrm{Ca}(\mathrm{OH})_{2}\right)$ and the consequent changes in human health risk. The bioavailable $\mathrm{F}$ decreased to $3.5 \%$, (i.e., $57.9 \pm 1.27 \mathrm{mg} / \mathrm{kg}$ in $6 \% \mathrm{Ca}(\mathrm{OH})_{2}$-treated soil sample) from $43.0 \%$, (i.e., $711 \pm 23.4 \mathrm{mg} / \mathrm{kg}$ in control soil sample). This resulted from the conversion of water-soluble $\mathrm{F}$ to stable calcium fluoride, which was confirmed by XRD spectrometry. Soil ingestion, inhalation of fugitive dust from soil, and water ingestion were selected as exposure pathways for human health risk assessment. Non-carcinogenic risks of $\mathrm{F}$ in soils reduced to less than 1.0 after stabilization, ranging from 4.2 to 0.34 for child and from 3.0 to 0.25 for adult. Contaminated water ingestion owing to the leaching of $\mathrm{F}$ from soil to groundwater was considered as a major exposure pathway. The risks through soil ingestion and inhalation of fugitive dust from soil were insignificant both before and after stabilization, although $\mathrm{F}$ concentration exceeded the Korean soil regulatory level before stabilization. Our data suggested that substantial risk to human health owing to various potential exposure pathways could be addressed by managing $\mathrm{F}$ present in soil.
\end{abstract}

Keywords: Calcium hydroxide, Fluorine, Human health risk assessment, Soil, Stabilization

\section{Introduction}

Fluorine (F) has received increasing attentions because of its high toxicity and reactivity [1, 2]. The Ministry of Environment has established the regulatory level of $\mathrm{F}$ at $400 \mathrm{mg} / \mathrm{kg}$ for residential and agricultural areas in the Korean Soil Environment Conservation Act [3]. Approximately 8 tons of highly toxic anhydrous hydrofluoric acid (AHF) was accidentally released from a chemical plant in Gumi, Korea into the environment on September 2012 [4]. AHF was rapidly converted to hydrogen fluoride $(\mathrm{HF})$ and it dispersed throughout the atmosphere, and spread to the surrounding environment, including soil and groundwater. The F released into the environment could induce human health problems unless properly managed. Damage to human health was caused by $\mathrm{HF}$ gas exposure immediately after the accident; however, chronic health impacts related to the $\mathrm{F}$ presenting in the soil have been exerted continuously [5, 6].

Many studies have clearly demonstrated that the role of bioavailable concentrations (i.e., water-soluble and leachable concentrations) may be more important in determining the toxic effects of $\mathrm{F}$ in soil than that of total $\mathrm{F}$ concentration $[7,8]$. Plant toxicity

This is an Open Access article distributed under the term of the Creative Commons Attribution Non-Commercial License (http://creativecommons.org/licenses/by-nc/3.0/) which permits unrestricted non-commercial use, distribution, and reproduction in any medium, provided the original work is properly cited.

Copyright (C) 2019 Korean Society of Environmental Engineers appeared to be considerably affected by water-soluble F concentrations in soil [9]. In addition, Geretharan et al. [10] observed that water-soluble $\mathrm{F}$ concentration is a key factor determining the retention and mobility of $\mathrm{F}$ in soil, and F concentration correlates with toxicity to soil microbes. Cronin et al. [5] suggested that the critical levels of the more bioavailable concentrations of $\mathrm{F}$ in soil, particularly in solution or in the water-soluble fraction, are probably the most important for toxicity and groundwater pollution. Bioavailable F concentrations should be considered for the proper risk management of F-contaminated soil.

Stabilization technology is a possible option for reducing the toxicity and mobility of contaminants in environmental media, including soil [11, 12]. Arsenic leaching from solid waste was successfully stabilized by binder materials including cement and fly ash [13], and steel slags [14]. The stabilization of Cd was tested using common amendment such as hydroxyapatite and biochar, and it was effectively immobilized in agricultural soils [15]. The reduction of extractable $\mathrm{Pb}, \mathrm{Cd}, \mathrm{Cu}$, and $\mathrm{Zn}$ from smelter contaminated soils by combined with lime was also investigated by Lahori et al. [16]. The term stabilization refers to a remediation process involving chemical reactions for reducing the leachability

Received September 30, 2018 Accepted January 3, 2019

${ }^{\dagger}$ Corresponding author

Email: dunee@kbsi.re.kr

Tel: +82-2-6943-4192 Fax: +82-2-6943-4149

ORCID: 0000-0001-9212-3208 
of the contaminants [17] by mixing a contaminated medium with a stabilizing agent [18]. An appropriate stabilizing agent can convert bioavailable $\mathrm{F}$ into chemically stable forms, thus preventing the spread of $\mathrm{F}$ contamination and reducing the risk to human health. Among various stabilizing agents, calcium-based stabilizing agents, such as calcium hydroxide $\left(\mathrm{Ca}(\mathrm{OH})_{2}\right)$, are most widely used to stabilize heavy metals as well as F [19-22]. The mechanism of $\mathrm{F}$ stabilization is explained by the reaction of $\mathrm{Ca}(\mathrm{OH})_{2}$ with $\mathrm{F}$ ions from $\mathrm{NaF}$ and $\mathrm{HF}$ resulting in insoluble calcium fluoride $\left(\mathrm{CaF}_{2}\right)$ formation, as shown in Eq. (1) [23].

$$
\mathrm{Ca}(\mathrm{OH})_{2}(\mathrm{aq})+2 \mathrm{~F}^{-} \rightarrow \mathrm{CaF}_{2}+2 \mathrm{OH}^{-}
$$

$\mathrm{CaF}_{2}$ is one of the most stable forms F-containing compounds, and sparingly soluble (0.016 g/L for $\left.\mathrm{CaF}_{2}\right)$, compared with $\mathrm{MgF}_{2}$ (0.13 g/L), $\mathrm{Na}_{3} \mathrm{AlF}_{6}(0.42 \mathrm{~g} / \mathrm{L}), \mathrm{HF}, \mathrm{SiF}_{4}$, and $\mathrm{NaF}$ (40 g/L) [24]. Most studies on F stabilization focused on water, such as F stabilization in groundwater, wastewater, and drinking water [25-27]. To date, the efficiency of F stabilization efficiency in soil and related changes in human health risk have not been fully demonstrated.

The study was aimed at evaluating the stabilization of F-contaminated soil in terms of human health risk, and providing insight for the risk-based management of F-contaminated soil. We investigated $\mathrm{F}$ stabilization in soil using $\mathrm{Ca}(\mathrm{OH})_{2}$, and to determine the consequent reduction of human health risk. Lab-scale batch experiments were performed to determine the stabilization efficiencies with $3 \%$ and $6 \% \mathrm{Ca}(\mathrm{OH})_{2}$. Modified sequential extraction was conducted to determine the stabilized $\mathrm{F}$ concentration in soil, and X-ray diffraction (XRD) analysis was performed to identify the F-containing compounds, such as $\mathrm{CaF}_{2}$, formed owing to stabilization. A human health risk assessment was performed, and changes in risks of $\mathrm{F}$ in soil from various exposure pathways were estimated before and after $\mathrm{F}$ stabilization.

\section{Experimental}

\subsection{Preparation and Characterization of Soil Sample}

Soil samples were collected from the area within a radius of $1 \mathrm{~km}$ from the site of accidental HF spillage in Gumi, Korea. Soil was sampled at a depth of 0-30 cm, air-dried, and passed through a $2 \mathrm{~mm}$ sieve to examine its physicochemical properties. Soil $\mathrm{pH}$ was measured at a soil:water ratio of 1:5, and organic matter content was determined using the Walkley-Black method [28]. Three textural fractions, namely clay, silt, and sand, were used to determine soil texture using the soil texture triangle recommended by the US Department of Agriculture (USDA). The total contents of 10 major elements (i.e., $\mathrm{Al}, \mathrm{Ca}, \mathrm{Fe}, \mathrm{K}, \mathrm{Mg}, \mathrm{Mn}, \mathrm{Na}, \mathrm{P}, \mathrm{Si}$, and $\mathrm{Ti}$ ) in the soil samples were analyzed using a wavelength dispersive X-ray fluorescence spectrometer (WD-XRF, PW2404, Phillips, Netherlands) at the Korea Basic Science Institute after preparing a glass bead using $\mathrm{Li}_{2} \mathrm{~B}_{4} \mathrm{O}_{7}$ (soil: $\mathrm{Li}_{2} \mathrm{~B}_{4} \mathrm{O}_{7}$ ratio of 1:10 (w/w)).

The $\mathrm{F}$ concentration in the soil samples was determined using the standard method of the Ministry of Korea, i.e., the UV/Visible spectrometric method [29]. Briefly, $1.0 \mathrm{~g}$ of soil sample was passed through a $75-\mu \mathrm{m}$ sieve and $1.0 \mathrm{~g}$ of soil and $5.0 \mathrm{~g}$ of $\mathrm{CaO}$ were placed in a nickel pot, in a furnace at $500^{\circ} \mathrm{C}$ for $5 \mathrm{~h}$ and $800^{\circ} \mathrm{C}$ for $2 \mathrm{~h}$. Then, $50 \mathrm{~mL}$ of $70 \% \mathrm{HClO}_{4}$ and $25 \mathrm{~mL}$ of deionized water were added to the residue obtained in the previous step, and $\mathrm{F}$ ions were extracted by distillation at $135 \pm 2{ }^{\circ} \mathrm{C}$. Subsequently, $50 \mathrm{~mL}$ of distilled sample was mixed with $10 \mathrm{~mL}$ sodium-2-(parasulfophenylazo)-dihydroxy-3, 6-napthalene disulfonate with zirconyl acid (Zr-SPADNS solution) in a $100 \mathrm{~mL}$ volumetric flask, and aliquots were analyzed using a spectrophotometer at $570 \mathrm{~nm}$. For determining $\mathrm{F}$ ion concentration in the solution, the standard method of the Ministry of Korea, i.e., ion selective electrode (ISE) method, was used [29]. After the preparation step described above, the filtrate was mixed with total ionic strength adjustment (TISAB) solution at a 1:1 ratio $(\mathrm{v} / \mathrm{v})$, and the mixture was analyzed using ISE (pH-270L, Istek, Korea).

A batch equilibrium experiment was conducted to determine the adsorption capacity of $\mathrm{F}$ onto the soil sample used in this study. In this, $1 \mathrm{~g}$ of soil sample and $25 \mathrm{~mL}$ of $\mathrm{NaF}$ solution (i.e., final F concentrations of 5, 10, 100, 250, 500, 1,000, 2,500, and 5,000 mg/L) were shaken for $24 \mathrm{~h}$ at room temperature. After centrifugation, the supernatant was collected, and F concentrations in equilibrium solution $(\mathrm{mg} / \mathrm{L})$ were determined using the ISE method. The weight of $\mathrm{F}$ adsorbed per unit weight of soil at equilibrium $(\mathrm{mg} / \mathrm{kg})$ was calculated. Saturation of F concentration adsorbed onto the soil sample in this study occurred when F solution (1,000 $\mathrm{mg} / \mathrm{L})$ was introduced thus, the soil sample was artificially contaminated with $1,000 \mathrm{mg} / \mathrm{L}-\mathrm{F}$ solution to simulate accidental spillage, and maximize stabilization efficiency. Therefore, $40 \mathrm{~g}$ of soil and $40 \mathrm{~mL}$ of $\mathrm{F}$ solution were mixed, followed by aging for $7 \mathrm{~d}$.

\subsection{F Stabilization Experiment Using $\mathrm{Ca}(\mathrm{OH})_{2}$}

A lab-scale batch experiment was conducted for $\mathrm{F}$ stabilization with $3 \%$ and $6 \% \mathrm{Ca}(\mathrm{OH})_{2}(\mathrm{w} / \mathrm{w})$, relative to the soil samples. Distilled water at field capacity (13.2\%) was added to the mixture of soil samples and $\mathrm{Ca}(\mathrm{OH})_{2}$, and agitated for $24 \mathrm{~h}$ at room temperature. The mixture was dried at room temperature, and four-step sequential extraction was performed to determine the soluble $\mathrm{F}$ concentration in the soil samples stabilized using $\mathrm{Ca}(\mathrm{OH})_{2}$. The four-step sequential extraction proposed by Xu et al. [30], was adopted to determine the stabilized $\mathrm{F}$ concentration in the soil samples. In the first step of the extraction of the water-soluble $\mathrm{F}$ fraction (fraction 1), $1 \mathrm{~g}$ of soil sample was stirred with $30 \mathrm{~mL}$ of distilled water for $15 \mathrm{~h}$ at $25 \pm 0.5^{\circ} \mathrm{C}$. Then, the residue was agitated with $30 \mathrm{~mL}$ of $20 \%(\mathrm{v} / \mathrm{v})$ acetic acid/water for $15 \mathrm{~h}$ at $25 \pm 0.5^{\circ} \mathrm{C}$ to extract the fraction of $\mathrm{F}$ bound to carbonates (fraction 2). Next, to determine the fraction of $\mathrm{F}$ bound to sulfides (fraction 3), the residue obtained from the second step was treated with $30 \mathrm{~mL}$ of $15 \%(\mathrm{v} / \mathrm{v})$ nitric acid/water in a covered vessel for $1 \mathrm{~h}$ at room temperature and for $1 \mathrm{~h}$ at $85^{\circ} \mathrm{C}$. Finally, the residual $\mathrm{F}$ fraction (fraction 4 ) was calculated by subtracting the $\mathrm{F}$ concentration obtained in steps 1 to 3 from the total $\mathrm{F}$ concentration determined using UV/Visible spectrometry. The sample obtained after each extraction step was centrifuged at approximately $5,000 \mathrm{~g}$, and filtered through a $0.45 \mu \mathrm{m}$ GHP filter. The $\mathrm{F}$ concentrations in the extracted solutions were determined using the ISE method. All experiments were performed in triplicate. 


\subsection{Human Health Risk Assessment}

\subsubsection{Exposure assessment and toxicity information}

A residential scenario was considered for the human health risk assessment, assuming that the contaminated site would be developed for residential and other anthropogenic activities after $\mathrm{F}$ stabilization. Direct exposure pathways, including soil ingestion, inhalation of fugitive dusts from soil, and water ingestion were considered. Additional exposure pathways (e.g., dermal contact) were ignored, because of the absence of a chemical-specific dermal absorption fraction $\left(\mathrm{ABS}_{\mathrm{d}}\right)$ for F. Similarly, the inhalation of volatile $\mathrm{F}$ in soils was neglected, because inorganic contaminants, excluding mercury, are regarded non-volatile compounds [31]. The exposure parameters for child and adult used in this study were obtained from the Korean soil contaminant risk assessment guidance [32] and Korean exposure factors handbook [33] (Table 1). Table 2 describes certain parameters used for calculating the particulate emission factor (PEF) for fugitive soil dust inhalation using Eq. (2).

$$
P E F=\frac{L S \times V \times D H \times \frac{3,600 S}{h r}}{A}
$$

Default values provided by the U.S. EPA were used for the site-specific parameters (e.g., width of contaminated area (LS), area of contamination (A), and fraction of vegetative cover (G)) and diffusion height (D)). The equivalent threshold value of wind speed at $700 \mathrm{~m}\left(\mathrm{U}_{\mathrm{t}}\right)$ and $\mathrm{F}(\mathrm{x})$ were determined following the method of Cowherd et al. [34] Mean annual wind speed $\left(U_{m}\right)$ was obtained from the Korea Meteorological Administration, and wind speed in the mixing zone $(\mathrm{V})$ was calculated from half of $\mathrm{U}_{\mathrm{m}}$.

Toxicity values for the human health risk assessment, such as oral reference dose (RfDo) and reference concentration (RfC) of $\mathrm{F}$ were obtained from the Integrated Risk Information System [35]

\begin{tabular}{|c|c|c|c|}
\hline & & Unit & Value \\
\hline \multicolumn{4}{|c|}{ Exposure parameters } \\
\hline IRSc & Soil ingestion rate - Child & $\mathrm{mg} / \mathrm{d}$ & 300 \\
\hline IRSa & Soil ingestion rate - Adult & $\mathrm{mg} / \mathrm{d}$ & 100 \\
\hline IRWC & Water ingestion rate - Child & $\mathrm{L} / \mathrm{d}$ & 0.78 \\
\hline IRWa & Water ingestion rate - Adult & $\mathrm{L} / \mathrm{d}$ & 2.5 \\
\hline EDc & Exposure duration for non-carcinogens - Child & $\mathrm{y}$ & 6 \\
\hline $\mathrm{EDa}$ & Exposure duration for non-carcinogens - Adult & $\mathrm{y}$ & 19 \\
\hline $\mathrm{EF}$ & Exposure frequency & $\mathrm{d} / \mathrm{y}$ & 350 \\
\hline ATc & Averaging time - Child & $\mathrm{d}$ & 2,190 \\
\hline ATa & Averaging time - Adult & $\mathrm{d}$ & 6,935 \\
\hline BWc & Body weight - Child & $\mathrm{kg}$ & 15 \\
\hline BWa & Body weight - Adult & $\mathrm{kg}$ & 63 \\
\hline ETrs & Soil exposure time - Soil inhalation pathway & $\mathrm{h} / \mathrm{d}$ & 1.3 \\
\hline $\mathrm{PEF}$ & Particulate emission factor & $\mathrm{m}^{3} / \mathrm{kg}$ & $1.47 \mathrm{E}+10$ \\
\hline \multicolumn{4}{|c|}{ Toxicity values } \\
\hline RfDo & Oral reference dose & $m g \mathrm{~kg}^{-1} \mathrm{~d}^{-1}$ & 0.060 \\
\hline $\mathrm{RfC}$ & Reference concentration & $\mathrm{mg} / \mathrm{m}^{3}$ & 0.013 \\
\hline
\end{tabular}

Table 1. Exposure Parameters and Toxicity Values of F Used in this Study

Table 2. Parameter Values Used to Calculate the PEF for Fugitive Dust Inhalation from Soil

\begin{tabular}{llcc}
\hline Parameters & & Unit & Value \\
\hline $\mathrm{LS}$ & Width of contaminated area & $\mathrm{m}$ & 45 \\
$\mathrm{~V}$ & Wind speed inmixing zone & $\mathrm{m} / \mathrm{s}$ & $\mathrm{m}$ \\
$\mathrm{DH}$ & Diffusion height & $\mathrm{m}^{2}$ & 2 \\
$\mathrm{~A}$ & Area of contamination & unitless & 2,025 \\
$\mathrm{G}$ & Fraction of vegetative cover & $\mathrm{m} / \mathrm{s}$ & 0.5 \\
$\mathrm{U}_{\mathrm{m}}$ & Mean annual wind speed & $\mathrm{m} / \mathrm{s}$ & 3.8 \\
$\mathrm{U}_{\mathrm{t}}$ & Equivalent threshold value of wind speed at $700 \mathrm{~m}$ & unitless & 11.3 \\
$\mathrm{~F}(\mathrm{x})$ & Function dependent on $\mathrm{U}_{\mathrm{m}} / \mathrm{U}_{\mathrm{t}}$ & & 0.0303 \\
\hline
\end{tabular}


and are shown in Table 1. Because F is classified as a non-carcinogenic element, carcinogenic toxicity values, including that of oral slope factor (SF), are not provided.

\subsubsection{Risk characterization}

The human health risk assessment for $\mathrm{F}$ were conducted following the U.S. EPA [36, 37]. Eq. (3), (4), and (5) presented below were used to estimate average daily $\mathrm{F}$ doses from soil ingestion, inhalation of fugitive dust from soil, and water ingestion, respectively.

$$
\begin{gathered}
A D D \text { s for soil ingestion }= \\
{[C s \times E F \times E D \times I R S] /[A T \times B W]} \\
A D E \text { for inhalation of fugitive dust from soil }= \\
{[C s \times E F \times E D \times E T r s] /[A T] \times[1 / P E F]} \\
A D D w \text { for water ingestion }= \\
{[C W \times E F \times E D \times I R W] /[A T \times B W]}
\end{gathered}
$$

where, $A D D s$ is average daily dose from soil ingestion $\left(\mathrm{mg} \mathrm{kg}^{-1} \mathrm{~d}^{-1}\right)$, $A D D w$ is average daily dose for water ingestion ( $\left.\mathrm{mg} \mathrm{L}^{-1} \mathrm{~d}^{-1}\right), A D E$ is average daily exposure $\left(\mathrm{mg} / \mathrm{m}^{3}\right), C s$ is the exposure concentration of $\mathrm{F}$ in soil (mg/kg), $\mathrm{CW}$ is the exposure concentration of $\mathrm{F}$ in water $(\mathrm{mg} / \mathrm{L}), I R S$ is soil ingestion rate $(\mathrm{mg} / \mathrm{d}), I R W$ is water ingestion rate $(\mathrm{L} / \mathrm{d}), E F$ is exposure frequency $(\mathrm{d} / \mathrm{y}), E D$ is exposure duration (y), $A T$ is averaging time (d), $B W$ is body weight (kg), ETrs is the soil exposure time for soil inhalation (h/d), and PEF is the particulate emission factor.

F concentration in groundwater was not measured in this study. Therefore, Cw, used to calculate the ADDw from water ingestion, was estimated using the soil-water phase partitioning equation for inorganic contaminants as follows in Eq. (6) [31, 38].

$$
C w=\frac{C s}{K_{d}+\frac{\theta_{w}+\theta_{a} H^{\prime}}{\rho_{b}}}
$$

where, $C w$ is the exposure concentration of $\mathrm{F}$ in groundwater $(\mathrm{mg} / \mathrm{L}), C s$ is the exposure concentration of $\mathrm{F}$ in soil $(\mathrm{mg} / \mathrm{kg})$, $K_{d}$ is the soil-water partition coefficient $(\mathrm{L} / \mathrm{kg}), \theta_{w}$ is water-filled soil porosity, $\theta_{a}$ is air-filled soil porosity, $\rho_{b}$ is the dry soil bulk density $(\mathrm{kg} / \mathrm{L})$, and $\mathrm{H}^{\prime}$ is Henry's constant. $\theta_{w}$ was estimated using Eq. (7), and $\theta_{a}$ was calculated as the difference between total porosity (n) and $\theta_{w} . n$ was expressed in terms of density according to Eq. (8).

$$
\begin{gathered}
\theta_{w}=\left(1-\frac{\rho_{b}}{2.65}\right)\left(\frac{I}{K_{s}}\right)^{1 /(2 b+3)} \\
n=1-\frac{\rho_{b}}{\rho_{s}}
\end{gathered}
$$

where, $\rho_{b}$ is the dry soil bulk density $(\mathrm{kg} / \mathrm{L}), K_{s}$ is the mean annual wind speed $(\mathrm{m} / \mathrm{y}), I$ is infiltration rate $(\mathrm{m} / \mathrm{y})$, and $1 /(2 b+3)$ is a constant (0.07), and $\rho_{s}$ is soil particle density $(\mathrm{kg} / \mathrm{L})$. Chemical-specific $K_{d}$ values were obtained from the generic table on regional screening level provided by U.S. EPA. Site-specific values such as $\rho_{b}, K_{s}$, and the constant [i.e., $\left.1 /(2 b+3)\right]$ were selected according to soil texture (loam) [39]; $\rho_{\mathrm{s}}$ was used as the Korean soil-specific value provided by the Rural Development Administration (RDA). Infiltration rate was $14.44 \%$ of the average annual precipitation, based on data obtained from the Korea Meteorological Administration, considering the groundwater recharge rate in Korea. The parameters used for calculating F concentration in groundwater are summarized in Table 3. A dilution attenuation factor was not considered for conservative risk calculation in this study.

The estimated exposure to $\mathrm{F}$ (i.e., $\mathrm{ADD}$ and $\mathrm{ADE}$ ) was divided by the toxicity values (i.e., RfDo and RfC). Total non-carcinogenic risks of $\mathrm{F}$ were determined based on the sum of the risk from soil ingestion, inhalation of fugitive dust from soil, and water ingestion and expressed as the hazard quotient (HQ; Eq. (9))

$$
\begin{gathered}
\text { Non-carcinogenic risk }(H Q)= \\
A D D / R f D o+A D E / R f C+A D D w / R f D o
\end{gathered}
$$

where, $H Q$ is the hazard quotient, $R f D o$ is the oral reference dose $\left(\mathrm{mg} \mathrm{kg}^{-1} \mathrm{~d}^{-1}\right), R f C$ is the reference concentration $\left(\mathrm{mg} / \mathrm{m}^{3}\right)$. If HQ exceeded one, it was generally considered that there might be a concern of non-carcinogenic effects.

Table 3. Parameter Values Used to Estimate F Concentration in Groundwater

\begin{tabular}{llcc}
\hline Parameters & & Unit & Value \\
\hline $\mathrm{K}_{\mathrm{d}}$ & Soil-water partition coefficient & $\mathrm{L} / \mathrm{kg}$ & 150 \\
$\theta_{\mathrm{w}}$ & Water-filled soil porosity & unitless & 0.24 \\
$\theta_{\mathrm{a}}$ & Air-filled soil porosity & unitless & 0.16 \\
$\mathrm{n}$ & Porosity & unitless & 0.4 \\
$\rho_{\mathrm{b}}$ & Dry soil bulk density & $\mathrm{kg} / \mathrm{L}$ & $\mathrm{kg} / \mathrm{L}$ \\
$\rho_{\mathrm{s}}$ & Soil particle density & $\mathrm{m} / \mathrm{y}$ & 2.65 \\
$\mathrm{~K}_{\mathrm{s}}$ & Saturated hydraulic conductivity & unitless & 60 \\
$1 /(2 \mathrm{~b}+3)$ & - & $\mathrm{m} / \mathrm{y}$ & 0.07 \\
$\mathrm{I}$ & Infiltration rate & unitless & 0.18 \\
$\mathrm{H}$ & Henry's law constant unitless & & 0
\end{tabular}




\section{Results and Discussion}

\subsection{Soil Characterization}

The physicochemical characteristics of the soil samples used in this study are summarized in Table $4 . \mathrm{pH}$ was 6.64 , and organic matter content was $13.1 \%$. The texture was loamy, with $44.9 \%$, $33.3 \%$, and $21.8 \%$ sand, silt, and clay, respectively. Elemental composition analysis using XRF showed that $\mathrm{SiO}_{2}$ content was the highest in the soil samples (76.9\%) among all detected compounds, followed by $\mathrm{Al}_{2} \mathrm{O}_{3}(10.7 \%), \mathrm{Fe}_{2} \mathrm{O}_{3}$ (2.68\%), and $\mathrm{K}_{2} \mathrm{O}$ $(2.63 \%)$ contents. Total $\mathrm{F}$ concentration in the soil sample was $1,654 \pm 7.36 \mathrm{mg} / \mathrm{kg}$. The modified sequential extraction results showed that the majority of $\mathrm{F}$ in the soil sample existed in a water-soluble form (i.e., a F concentration of $711 \pm 23.4 \mathrm{mg} / \mathrm{kg}$

Table 4. Physicochemical Properties of the Soil Sample Used in this Study

\begin{tabular}{lcc}
\hline Properties & Unit & Values \\
\hline Total F concentration & $\mathrm{mg} / \mathrm{kg}$ & $1,654 \pm 7.36$ \\
Water soluble (fraction 1) & & $711 \pm 23.4$ \\
Bound to carbonates (fraction 2) & & $1.00 \pm 0.171$ \\
Bound to sulfide compounds (fraction 3) & & $0.00004 \pm 0.00004$ \\
Residual (fraction 4) & & $942 \pm 23.6$ \\
\hline $\mathrm{pH}$ & - & 6.64 \\
Organic matter contents & $\%$ & 13.1 \\
Sand contents & $\%$ & 44.9 \\
Silt contents & $\%$ & 33.3 \\
Clay contents & $\%$ & 21.8 \\
Texture & - & Loam \\
\hline
\end{tabular}

\section{Elemental composition}

$\begin{array}{lcc}\mathrm{Al}_{2} \mathrm{O}_{3} & \% & 10.7 \\ \mathrm{CaO} & \% & 0.275 \\ \mathrm{Fe}_{2} \mathrm{O}_{3} & \% & 2.68 \\ \mathrm{~K}_{2} \mathrm{O} & \% & 2.63 \\ \mathrm{MgO} & \% & 0.574 \\ \mathrm{MnO} & \% & 0.029 \\ \mathrm{Na}_{2} \mathrm{O} & \% & 0.690 \\ \mathrm{P}_{2} \mathrm{O}_{5} & \% & 0.135 \\ \mathrm{SiO}_{2} & \% & 76.9 \\ \mathrm{TiO}_{2} & \% & 0.55 \\ \mathrm{L.O.I}^{*} & \% & 5.70\end{array}$

*loss on ignition on average, and $43.0 \%$ in fraction 1) and as residue (i.e., 942 $\pm 23.6 \mathrm{mg} / \mathrm{kg}$ on average and $57.0 \%$ in fraction 4 ). On average, only $0.060 \%$ and $0.00002 \% \mathrm{~F}$ was bound to carbonates $(1.00 \pm$ $0.171 \mathrm{mg} / \mathrm{kg}$ in fraction 2) and sulfides (0.00004 $\pm 0.00004 \mathrm{mg} / \mathrm{kg}$ in fraction 3), respectively. Many researchers have investigated the relationship between the bioavailability (i.e., leachability or mobility) of heavy metals, as well as for F, and their chemical forms in soils. It is widely recognized that heavy metals, as well as $\mathrm{F}$, are most toxic and mobile in their water-soluble form (fraction 1), and it is unlikely that in the residue form (fraction 4), it is accessible to living organisms, or exhibits any toxic effects [8, 40-42]. The leachable $\mathrm{F}$ concentration for stabilization in the soil samples used in this study was $711 \pm 23.4 \mathrm{mg} / \mathrm{kg}$ (i.e., water-soluble F in fraction 1); furthermore, this concentration exceeded the regulatory soil $\mathrm{F}$ level set in the Korean Soil Environment Conservation Act (i.e., $400 \mathrm{mg} / \mathrm{kg}$ ) [3].

\subsection{F Stabilization in Soil Using $\mathrm{Ca}(\mathrm{OH})_{2}$}

Table 5 showed that when $3 \%$ and $6 \% \mathrm{Ca}(\mathrm{OH})_{2}$ were added to the soil samples, the chemical forms of $\mathrm{F}$ changed, compared with the untreated soil sample (i.e., control soil sample). Importantly, the bioavailable $\mathrm{F}$ concentration related to fraction 1 decreased to $3.7 \%$ and $3.5 \%$ on average $(61.2 \pm 1.65$ and 57.9 $\pm 1.27 \mathrm{mg} / \mathrm{kg}$ in the $3 \%$ and $6 \% \mathrm{Ca}(\mathrm{OH})_{2}$-treated soil samples, respectively) from $43.0 \%(711 \pm 23.4 \mathrm{mg} / \mathrm{kg}$ in the control soil sample). Nearly all of the total $\mathrm{F}$ was present in the residue form (i.e., fraction 4) in the $\mathrm{Ca}(\mathrm{OH})_{2}$-treated soil samples. The ratio of $\mathrm{F}$ as residue increased markedly to $95.8 \%$ and $95.9 \%$ on average $(1,584 \pm 2.33$ and $1,586 \pm 1.31 \mathrm{mg} / \mathrm{kg}$ in the $3 \%$ and $6 \%$ $\mathrm{Ca}(\mathrm{OH})_{2}$-treated soil samples, respectively), compared with $57.0 \%$ on average (942 $\pm 23.6 \mathrm{mg} / \mathrm{kg}$ in the control soil sample). This indicated that most of the leachable $\mathrm{F}$ was converted into stable forms, such as $\mathrm{CaF}_{2}$ in the $\mathrm{Ca}(\mathrm{OH})_{2}$-treated soil samples; thus, $\mathrm{Ca}(\mathrm{OH})_{2}$ successfully acted as the stabilizing agent for $\mathrm{F}$ in the soil sample. The leachable concentrations $\mathrm{F}$ in the $\mathrm{Ca}(\mathrm{OH})_{2}$-treated soil samples were observed to be within the Korean soil regulatory level (i.e., $400 \mathrm{mg} / \mathrm{kg}$ ) [3]. Meanwhile, there was no significant difference in stabilization between the $3 \%$ and $6 \% \mathrm{Ca}(\mathrm{OH})_{2}$-treated soil samples.

$\mathrm{Ca}$ and $\mathrm{F}$ are known to form precipitates, such as $\mathrm{CaF}_{2}$, which could contribute to $\mathrm{F}$ stabilization [23, 43]. $\mathrm{CaF}_{2}$ formation in the $\mathrm{Ca}(\mathrm{OH})_{2}$-treated soil samples was detected by XRD. XRD patterns were compared between an untreated soil sample and a $6 \% \mathrm{Ca}(\mathrm{OH})_{2}$-treated soil sample contaminated with $1.64 \%$ of $\mathrm{F}$, and $\mathrm{CaF}_{2}$ mineral served as the control. Because the low $\mathrm{F}$ concentration in the soil used in this study (i.e., 1,654 $\pm 7.36 \mathrm{mg} / \mathrm{kg}$ of $\mathrm{F}$ contaminated soil sample) resulted in low sensitivity, it could not

Table 5. F Concentrations in Soil Samples Determined By Modified Sequential Extraction

\begin{tabular}{lccc}
\hline F concentration $(\mathbf{m g} / \mathbf{k g})$ & Control soil & Soil with $\mathbf{3} \% \mathbf{C a}(\mathbf{O H})_{2}$ & Soil with $\mathbf{6 \%} \mathbf{C a}(\mathbf{O H})_{2}$ \\
\hline Fraction 1 & $711 \pm 23.4$ & $61.2 \pm 1.65$ & $57.9 \pm 1.27$ \\
Fraction 2 & $1.00 \pm 0.171$ & $8.00 \pm 0.764$ & $9.37 \pm 0.255$ \\
Fraction 3 & $0.00004 \pm 0.00004$ & $0.043 \pm 0.004$ & $0.036 \pm 0.001$ \\
Fraction 4 & $942 \pm 23.6$ & $1,584 \pm 2.33$ & $1,586 \pm 1.31$ \\
\hline
\end{tabular}




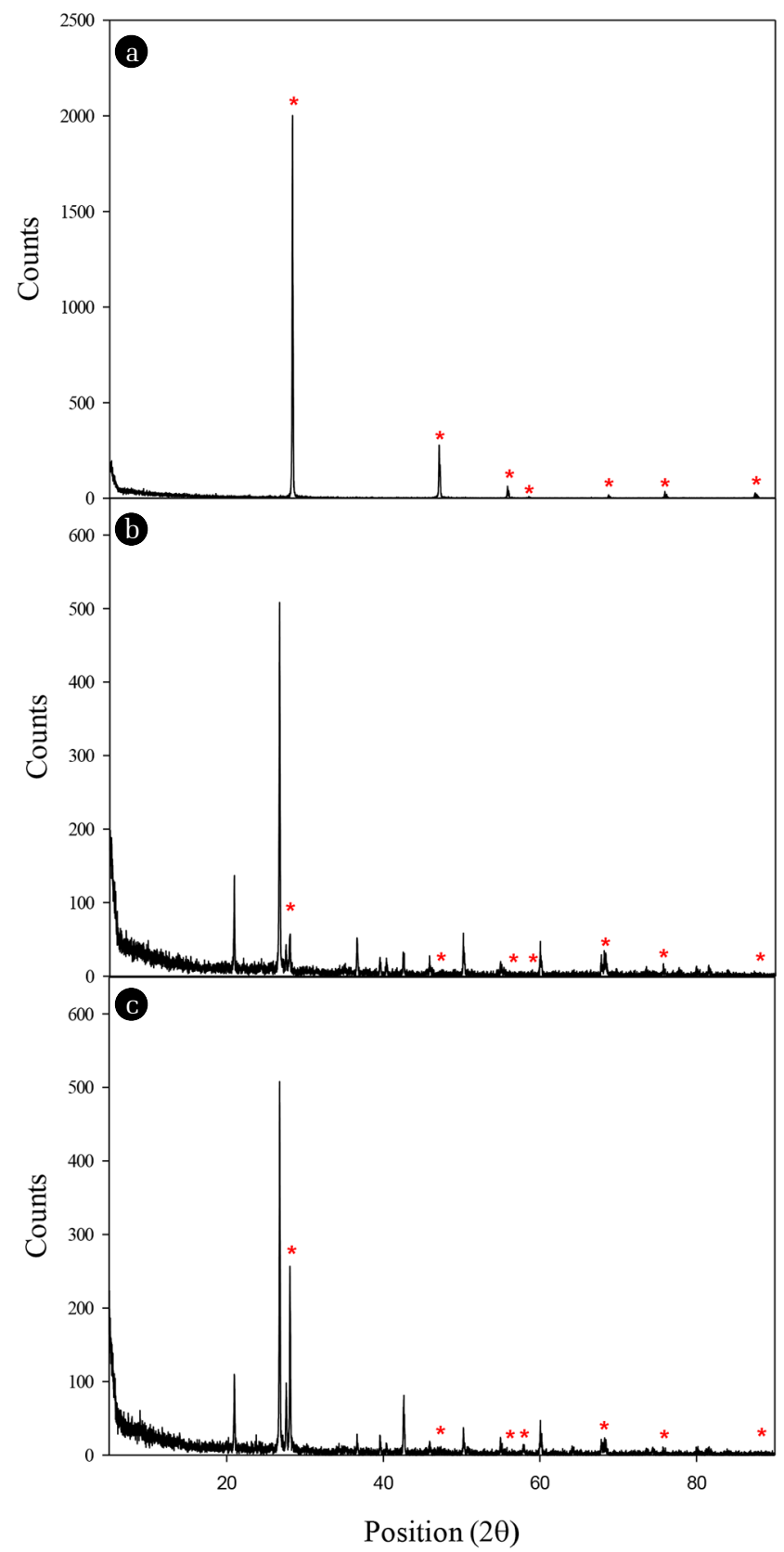

Fig. 1. XRD patterns of $\mathrm{CaF}_{2}$ (a), control soil sample contaminated with $1.64 \%$ of fluorine (untreated soil sample) (b), and $\mathrm{Ca}(\mathrm{OH})_{2}$-treated soil sample contaminated with $1.64 \%$ of fluorine (c).

be detected by XRD; the soil sample contaminated with a high $\mathrm{F}$ concentration (1.64\%), considering the solubility of $\mathrm{NaF}$, was used for the noticeable detection of $\mathrm{CaF}_{2}$ formation. Fig. 1 showed that a significantly higher extent of $\mathrm{CaF}_{2}$ formation was observed in the $\mathrm{Ca}(\mathrm{OH})_{2}$-treated soil samples than in the untreated soil samples. Because the soil samples used in this study had low Ca contents, most of the $\mathrm{CaF}_{2}$ produced resulted from $\mathrm{Ca}(\mathrm{OH})_{2}$ addition. Aldaco et al. [44] observed that while adding doses of calcium ions to fluoride present in wastewater, the ions $\left(\mathrm{Ca}^{2+}\right.$ and $\left.\mathrm{F}^{-}\right)$form an insoluble product $\left(\mathrm{CaF}_{2}\right)$. Additionally, $\mathrm{CaF}_{2}$ formation confirmed the possibility of $\mathrm{CaF}_{2}$ precipitate formation in the reaction between calcium ions and soluble $\mathrm{F}$ present in soil using PHREEQC, a geochemical model [45].

\subsection{Effect of $F$ Stabilization on Human Health Risk Reduction}

A human health risk assessment was performed to evaluate the effect of $\mathrm{F}$ stabilization in soil on risk reduction. Because similar stabilization efficiencies were observed for the $3 \%$ and $6 \%$ $\mathrm{Ca}(\mathrm{OH})_{2}$-treated soil samples, only $6 \% \mathrm{Ca}(\mathrm{OH})_{2}$-treated soil samples, having a relatively higher stabilization efficiency compared with that of $3 \% \mathrm{Ca}(\mathrm{OH})_{2}$, were used for risk calculation in this study. Water-soluble F concentration, in fraction 1 determined by sequential extraction in this study, was considered the exposure concentration (e.g., Cs) for calculating ADDs and ADE. The exposure concentration used for risk calculation is presented in Table 6. The estimated HQ of $F$ to non-carcinogenic human health risk under the stabilization conditions used is shown in Table 7. Non-carcinogenic risk was expected in the control soil samples (i.e., untreated soil sample), however the total risk reduced to less than 1.0 when the soil samples were treated with $\mathrm{Ca}(\mathrm{OH})_{2}$ for both children and adults, suggesting that the potential risk reduced. Total HQ values were the highest in the control soil samples for children (4.2), followed by the control soil samples for adults (3.0), $\mathrm{Ca}(\mathrm{OH})_{2}$-treated soil samples for children (0.34) and $\mathrm{Ca}(\mathrm{OH})_{2}$-treated soil samples for adults (0.25). Majority of the non-carcinogenic risk to children and adults in the control soil samples resulted from water ingestion, corresponding to 3.9 and 3.0, respectively. When the soil sample were treated with $\mathrm{Ca}(\mathrm{OH})_{2}$, the risk from water ingestion decreased sharply to 0.32 and 0.24 for children and adults, respectively. Interestingly, non-carcinogenic risk owing to soil ingestion was not expected in the control soil sample, although the exposure concentrations of $\mathrm{F}$ in soil $(711 \mathrm{mg} / \mathrm{kg})$ exceeded the Korean soil F regulatory level et in the Korean Soil Environment Conservation Act (i.e., $400 \mathrm{mg} / \mathrm{kg}$ ) [3]. The HQ values resulting from soil ingestion were 0.23 and 0.018 in the control soil samples for children and adults, respectively. The $\mathrm{HQ}$ values of the $\mathrm{Ca}(\mathrm{OH})_{2}$-treated soil samples were lower than those of the control soil samples (0.019 and 0.0015 for children and adults, respectively). This indicated that the Korean soil F regulatory level might be excessively conservative. The regional screening levels (RSLs) superfund sites is set by the U.S. EPA as $3,100 \mathrm{mg} / \mathrm{kg}$ in residential soil for children based on non-carcinogenic risk, i.e., $\mathrm{HQ}<1$ [35]. The contribution of inhalation of fugitive dust from soil to non-carcinogenic risk was negligible for children and adults, i.e., $1.9 \times 10^{-7}$ and 1.6 $\times 10^{-8}$ in the $\mathrm{Ca}(\mathrm{OH})_{2}$-treated and control soil samples, respectively. Most importantly, our results revealed that the $\mathrm{F}$ leaching from soil into groundwater is a critical pathway contributing to the high risk of contaminated water ingestion; therefore, the investigation of groundwater at a nearby site is essential for risk management for F-contaminated soil. Additionally, the reduction of non-carcinogenic risk from all exposure pathways upon soil treatment with $\mathrm{Ca}(\mathrm{OH})_{2}$ demonstrated that stabilization is an effective technique for the remediation of $\mathrm{F}$-contaminated soil. 
Table 6. Exposure Concentrations of $\mathrm{F}$ Used to Calculate Human Health Risk

\begin{tabular}{lccccc}
\hline \multirow{2}{*}{ Soil samples } & \multicolumn{3}{c}{ Cs $(\mathbf{m g} / \mathbf{k g})$} & \multicolumn{2}{c}{$\mathbf{C w}(\mathbf{m g} / \mathbf{L})$} \\
\cline { 2 - 3 } & Control soil & Soil with $\mathbf{6 \%} \mathbf{C a}(\mathbf{O H})_{2}$ & & Control soil & Soil with 6\% Ca(OH) \\
\hline Values (on average) & 711 & 57.9 & 4.73 & 0.385 \\
\hline
\end{tabular}

Table 7. Estimated Risks (HQ) Depending on Various Exposure Pathways for Soil Samples Used. HQ Values that Exceeded 1.0 are Represented in Bold

\begin{tabular}{lccccc}
\hline Exposure pathway & \multicolumn{2}{c}{ Control soil } & \multicolumn{3}{c}{ Soil with $\mathbf{6 \%} \mathbf{C a}(\mathbf{O H})_{2}$} \\
\hline Receptor & Child & Adult & \multicolumn{2}{c}{ Child } & Adult \\
\hline Soil ingestion & $2.3 . E-01$ & $1.8 . E-02$ & $1.9 . E-02$ & $1.5 . E-03$ \\
Fugitive dust inhalation & $1.9 . E-07$ & $1.9 . E-07$ & $1.6 . E-08$ & $1.6 . E-08$ \\
Water ingestion & $\mathbf{3 . 9 . E + 0 0}$ & $\mathbf{3 . 0 . E + 0 0}$ & $3.2 . E-01$ & $2.4 . E-01$ \\
\hline Total HQ & $\mathbf{4 . 2 . E + 0 0}$ & $\mathbf{3 . 0 . E + 0 0}$ & $3.4 . E-01$ & $2.5 . E-01$ \\
\hline
\end{tabular}

\section{Conclusions}

In this study, $\mathrm{F}$ stabilization was conducted using $\mathrm{Ca}(\mathrm{OH})_{2}$, and the reduction in human health risk was estimated by conducting a human health risk assessment. The bioavailable $\mathrm{F}$ concentration decreased remarkably, and this resulted from conversion of water-soluble $\mathrm{F}$ into stable $\mathrm{CaF}_{2}$. The non-carcinogenic risks (HQ) of $\mathrm{F}$ in soil to children and adults decreased to less than 1.0 after stabilization. The ingestion of F-contaminated water, caused by $\mathrm{F}$ leaching from soil into groundwater, contributes more to the risk than do other exposure types, such as soil ingestion and inhalation of fugitive dust from soil. The risk from soil ingestion made a smaller contribution to the total non-carcinogenic risk, although there is a stringent soil F regulatory level in Korea. These findings indicated that stabilization could be an effective option for reducing risk from F-contaminated soil, and a more realistic and reasonable management strategy in terms of soil regulatory level and investigation of contaminated sites should be developed based on the human health risk posed by the contaminant.

\section{Acknowledgments}

This work was supported by the Geo-Advanced Innovative Action (GAIA) Project of the Korea Environmental Industry and Technology Institute (KEITI).

\section{References}

1. Chouhan S, Flora S. Arsenic and fluoride: Two major ground water pollutants. Indian J. Exp. Biol. 2010;48:666-678.

2. Li L, Luo KL, Liu YL, Xu YX. The pollution control of fluorine and arsenic in roasted corn in "coal-burning" fluorosis area Yunnan, China. J. Hazard. Mater. 2012;229:57-65.

3. KMOE (Korea Ministry of Environment). Soil Environment Conservation Act: 11464. Sejong, Republic of Korea (in Korean); 2013.
4. Lim HS, Lee K. Health care plan for hydrogen fluoride spill, Gumi, Korea. J. Korean Med. Sci. 2012;27:1283-1284.

5. Cronin S, Manoharan V, Hedley M, Loganathan P. Fluoride: eo review of its fate, bioavailability, and risks of fluorosis in grazed pasture systems in New Zealand. New Zeal. J. Agr. Res. 2000;43:295-321.

6. An J, Kim KH, Yoon HO, Seo J. Application of the wavelength dispersive X-ray fluorescence technique to determine soil fluorine with consideration of iron content in the matrix. Spectrochim. Acta Part B. At. Spectrosc. 2012;69:38-43.

7. Yang K, Jeong S, Jho EH, Nam K. Effect of biogeochemical interactions on bioaccessibility of arsenic in soils of a former smelter site in Republic of Korea. Environ. Geochem. Health 2016;38:1347-1354.

8. Jeong S, Yang K, Jho EH, Nam K. Importance of chemical binding type between As and iron-oxide on bioaccessibility in soil: Test with synthesized two line ferrihydrite. J. Hazard. Mater. 2017;330:157-164.

9. An J, Lee HA, Lee J, Yoon HO. Fluorine distribution in soil in the vicinity of an accidental spillage of hydrofluoric acid in Korea. Chemosphere 2015;119:577-582.

10. Geretharan T, Jeyakumar P, Anderson C, Bretherton M. Effects of soil properties on bioavailability of fluorine to microorganisms [dissertation]. Fertilizer and Lime Research center; Palmerston North: Massey Univ.; 2017.

11. Alpaslan B, Yukselen MA. Remediation of lead contaminated soils by stabilization/solidification. Water. Air. Soil. Pollut. 2002;133:253-263.

12. Sasaki K, Nagato S, Ideta K, Miyawaki J, Hirajima T. Enhancement of fluoride immobilization in apatite by $\mathrm{Al}^{3+}$ additives. Chem. Eng. J. 2017;311:284-292.

13. Singh TS, Pant K. Solidification/stabilization of arsenic containing solid wastes using portland cement, fly ash and polymeric materials. J. Hazard. Mater. 2006;131:29-36.

14. Kim SH, Jeong S, Chung H, Nam K. Stabilization mechanism of arsenic in mine waste using basic oxygen furnace slag: The role of water contents on stabilization efficiency. Chemosphere 2018;208:916-921.

15. Guo F, Ding C, Zhou Z, Huang G, Wang X. Stability of immobilization remediation of several amendments on cadmium con- 
taminated soils as affected by simulated soil acidification. Ecotoxicol. Environ. Saf. 2018;161:164-172.

16. Lahori AH, Zhang Z, Guo Z, et al. Potential use of lime combined with additives on (im)mobilization and phytoavailability of heavy metals from $\mathrm{Pb} / \mathrm{Zn}$ smelter contaminated soils. Ecotoxicol. Environ. Saf. 1027;145:313-323.

17. EPA USA. Solidification/stabilization use at superfund sites in Office of Solid Waste and Emergency Response. Washington D.C.; Technology Innovation Office; 2000.

18. EPA USA. A citizen's guide to solidification and stabilization. Washington D.C.; Office of Solid Waste and Emergency Response; 2012.

19. Kang WH, Kim EI, Park JY. Fluoride removal capacity of cement paste. Desalination 2007;202:38-44.

20. Chen Q, Tyrer M, Hills CD, Yang X, Carey P. Immobilization of heavy metal in cement-based solidification/stabilisation: a review. Waste Manage. 2009;29:390-403.

21. Ponsot I, Falcone R, Bernardo E. Stabilization of fluorine-containing industrial waste by production of sintered glassceramics. Ceram. Int. 2013;39:6907-6915.

22. Chlopecka A, Adriano DC. Mimicked in-situ stabilization of metals in a cropped soil: Bioavailability and chemical form of zinc. Environ. Sci. Technol. 1996;30:3294-3303.

23. Jadhav SV, Bringas E, Yadav GD, et al. Arsenic and fluoride contaminated groundwaters: A review of current technologies for contaminants removal. J. Environ. Manage. 2015;162:306-325.

24. Pickering W. The mobility of soluble fluoride in soils. Environ. Pollut. B. 1985;9:281-308.

25. Islam M, Patel R. Evaluation of removal efficiency of fluoride from aqueous solution using quick lime. J. Hazard. Mater. 2007:143:303-310.

26. Mohapatra M, Anand S, Mishra BK, Giles DE, Singh P. Review of fluoride removal from drinking water. J. Environ. Manage. 2009:91:67-77.

27. Tchomgui-Kamga E, Ngameni E, Darchen A. Evaluation of removal efficiency of fluoride from aqueous solution using new charcoals that contain calcium compounds. J. Colloid Interface Sci. 2010;346:494-499.

28. Walkley A, Black IA. An examination of the Degtjareff method for determining soil organic matter, and a proposed modification of the chromic acid titration method. Soil Sci. 1934;37:29-38.

29. KMOE (Korea Ministry of Environment). Korean Standard Test Method for Soil. Gwacheon; ECOREA; 2009. (in Korean)

30. Xu L, Luo K, Feng F, Tan JA. Studies on the chemical mobility of fluorine in rocks. Fluoride 2006;39:145-151.

31. EPA USA. Soil screening guidance: Technical background document. Office of Solid Waste and Emergency Response;
Washington D.C.; 1996.

32. KMOE (Korea Ministry of Environment). Soil contaminant risk assessment guidance: 2011-139. Gwacheon, Republic of Korea (in Korean), 2011.

33. Jang JY, Kim SY, Kim SJ, et al. General factors of the Korean exposure factors handbook. J. Prev. Med. Public Health 2014;47:7-17.

34. Cowherd C, Muleski GE, Englehart PJ, Gillette DA. Rapid assessment of exposure to particulate emissions from surface contamination sites. Kansas City; Midwest Research Institute; 1984.

35. U.S. EPA. Regional screening table: User's guide. [cited 19 Jan 2017]. Available from: http://www.epa.gov/risk/regional-screening-levels-rsls-generic-tables-november-2017.

36. U.S. EPA. Risk assessment guidance for superfund (RAGS), Volume I: Human Health Evaluation Manual (Part A), Washington D.C.; Office of Emergency and Remedial Response; 1989.

37. U.S. EPA. Soil Screening Guidance: User's guide, Office of Solid Waste and Emergency Response; Washington D.C.; 1996.

38. ASTM. Standard guide for risk-based corrective action applied at petroleum release sites. West Conshokocken; ASTM International; 2010.

39. U.S. EPA. User's Guide for Evaluating Subsurface Vapor Intrusion into Buildings. Washington D.C.; Office of Emergency and Remedial Response; 2004.

40. Tack F, Verloo MG. Chemical speciation and fractionation in soil and sediment heavy metal analysis: A review. Int. J. Environ. Anal. Chem. 1995;59:225-238.

41. Rodríguez L, Ruiz E, Alonso-Azcárate J, Rincón J. Heavy metal distribution and chemical speciation in tailings and soils around a $\mathrm{Pb}-\mathrm{Zn}$ mine in Spain. J. Environ. Manage. 2009;90:1106-1116.

42. Violante A, Cozzolino V, Perelomov L, Caporale A, Pigna M. Mobility and bioavailability of heavy metals and metalloids in soil environments. J. Soil Sci. Plant Nutr. 2010;10:268-292.

43. Markovic M, Takagi S, Chow LC, Frukhtbeyn S. Calcium fluoride precipitation and deposition from $12 \mathrm{mmol} / \mathrm{L}$ fluoride solutions with different calcium addition rates. J. Res. Natl. Inst. Stand. Technol. 2009;114:293-301.

44. Aldaco R, Garea A, Irabien A. Calcium fluoride recovery from fluoride wastewater in a fluidized bed reactor. Water Res. 2007;41:810-818.

45. Kwon E, Lee HA, Kim D, Lee J, Lee S, Yoon HO. Geochemical investigation of fluoride migration in the soil affected by an accidental hydrofluoric acid leakage. J. Soil. Groundw. Environ. 2015;20:65-73. 